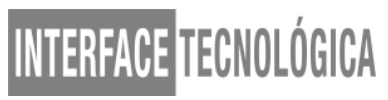

\title{
A IMPORTÂNCIA DE ALIMENTOS GENETICAMENTES MODIFICADOS PARA O AGRONEGÓCIO
}

\section{THE IMPORTANCE OF GENETICALLY MODIFIED FOODS FOR AGRIBUSINESS}

\author{
Viviane Pereira da Silva - vivi.psil2@gmail.com \\ Faculdade de Tecnologia de Taquaritinga - Taquaritinga - São Paulo - Brasil \\ Fabio Alexandre Cavichioli - fabio.cavichioli@fatectq.edu.br \\ Faculdade de Tecnologia de Taquaritinga - Taquaritinga - São Paulo - Brasil \\ DOI: 10.31510/infa.v18i1.1134 \\ Data de submissão: 16/04/2021 \\ Data do aceite: 09/07/2021 \\ Data da publicação: 30/07/2021
}

\begin{abstract}
RESUMO
Os produtores rurais tiveram seus lucros exponenciais, devido ao plantio de variantes genéticas modificadas, pois as mesmas reduzem os custos, aumenta a área produtiva em hectares, sendo mais resistentes que as variantes convencionais. Outro aspecto importante condiz com expansão populacional, fazendo com que os Organismos Geneticamente Modificados, sejam um forte aliado para o fornecimento de alimento em decorrência das estimativas de crescimento exponencial no que concerne a quantidade de pessoas no mundo. Este artigo é uma revisão bibliográfica, que tem como objetivo discutir a utilização da biotecnologia moderna em relação aos organismos geneticamente modificados e sua importância para o agronegócio e propulsão da economia em todo país. Ao longo do estudo será discorrido a história da biotecnologia, a evolução da mesma, surgimento e adoção de OGMs nos países A falta de informações faz com que muitas pessoas rechaça a utilização desses organismos, mas dados de relatórios mundiais constaram durante anos de estudo que o mesmo não polui o ambiente e são iguais as variantes convencionais. A ciência existe para auxiliar na evolução e melhorias de vida das pessoas, buscando informações sérias e contundentes. É fato que transgênicos, que são organismos modificados vieram para ficar, e no geral só trouxeram lucratividade e produtividade ao agronegócio, refletindo em vários setores na economia e geração de empregos.
\end{abstract}

Palavras-chave: Biotecnologia. Alimentação. Economia.

\begin{abstract}
This article is a bibliographic review, which aims to discuss the use of modern biotechnology in relation to genetically modified organisms and their importance for agribusiness and propulsion of the economy throughout the country. Throughout the study, the history of biotechnology, its evolution, the emergence, and adoption of Genetically Modified Organisms in countries will be discussed. Rural producers had their exponential profits, due to the planting of modified genetic variants, as they reduce costs, increase the productive area in hectares,
\end{abstract}


being more resistant than conventional variants. Another important aspect is consistent with population expansion, making GMOs a strong ally for the supply of food due to estimates of exponential growth in terms of the number of people in the world. The lack of information causes many people to reject the use of these organisms, but data from world reports have shown during years of study that it does not pollute the environment and the conventional variants are the same. Science exists to assist in the evolution and improvement of people's lives, seeking serious and overwhelming information. It is a fact that transgenics, which are modified organisms are here to stay, and in general have only brought profitability and productivity to agribusiness, reflecting in various sectors in the economy and job creation.

Keywords: Biotechnology. Food. Economy

\section{INTRODUÇÃO}

O aumento populacional mundial tem levantado muitos questionamentos em relação ao modo de produção de alimentos. Segundos dados divulgados pela Organização das Nações Unidas (ONU), em 2050 estima-se que a população atinja 9,7 milhões de pessoas, o que tornaria uma jornada complexa em relação a como produzir alimentos para toda essa geração por meio da agricultura convencional, levando em consideração a quantidade de hectares disponível para plantação sem que tenha um impacto no meio ambiente.

Os Alimentos Geneticamente Modificado surgiram juntamente com os avanços tecnológicos que contribuíram com os aumentos produtivos agrícolas, com características como resistências a pragas e doenças, ou com variedades características de produtividade (PAIVA E DAMASCENO, 2020).

Organismos Geneticamente Modificados são os organismos que possuem o seu material genético modificado, por meio de introdução de um ou mais genes para a aquisição de uma característica que antes não seria possível adquirir por métodos convencionais, ou melhoramento de alguma característica já existente por meio de técnicas atribuídas por biologia molecular (CAMARA et al., 2009). Podem ser atribuídas características em plantas como o melhoramento de produtividade, resistência contra algum tipo de praga ou doenças, resistência as condições dos mais diversos climas e temperatura, além de adição de alguma característica que eleve o nível nutricional (PAIVA E DAMASCENO, 2020).

Por um lado, entra o questionamento na efetividade dos métodos utilizados para a liberação dos produtos por meio dos órgãos regulamentadores. Sendo assim, entra em 


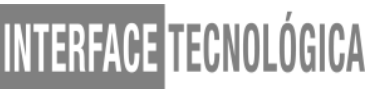

indagação o quanto pode ajudar ou prejudicar o consumo de Alimentos Geneticamente Modificados, quais são os seus impactos no meio ambiente e na saúde da população.

O objetivo deste artigo, é realizar uma análise de aspectos envolvendo o uso de Organismos Geneticamente Modificado e os seus impactos para o Agronegócio em relação ao crescente aumento populacional, levando em consideração informações adicionais sobre a veracidade e qualidade destes Alimentos Geneticamente Modificado (AGM) para a saúde de

toda a população em geral.

\section{REFERNCIAL TEÓRICO}

\subsection{BIOTECNOLOGIA E OS ORGANISMOS GENETICAMENTE MODIFICADO} (OGMs)

\subsubsection{Biotecnologia contexto histórico}

As sociedades independentes da época criam e aperfeiçoam ferramentas, técnicas e métodos, com seu intelecto com o intuito de melhorar suas condições de vida e aumentar o consumo transformando o mundo de acordo com seus interesses e necessidades que vão além do simples ato de sobreviver. Tais artefatos utilizados pelo homem para moldar o ambiente reinventando-se são chamados tecnologia. Desta forma biotecnologia segundo a Organização Mundial da Saúde (OMS, 2008) no ano de 1992, definiu-a como sendo "qualquer aplicação tecnológica que usa sistemas biológicos, organismos vivos ou seus derivados, para criar ou modificar produtos e processos para usos específicos".

Apesar da biotecnologia ser considerada uma técnica inovadora, era utilizada por babilônios e sumérios na antiguidade clássica 6000 a.c., com fungos chamados de levedura no processo de fermentação da cerveja. Já no Egito antigo tal processo fermentativo era utilizada para a produção e posteriormente na aplicação e fabricação de queijos, iogurtes, vinhos e vinagres, todavia os organismos que possibilitavam tais processos não eram conhecidos. (MALAJOVICH, 2016)

Tempos depois Antony Van Leeuwenhoek observou com um microscópio primitivo e verificou a existência de seres invisíveis a olho nu, que são os protozoários e bactérias e os mesmos de certa forma poderiam fazer parte do processo de fermentação. A comprovação de que a fermentação era causada por microrganismos ocorreu no século 19, com os experimentos 
do biólogo Louis Pasteur, onde vigorava a teoria da geração espontânea ou abiogênese. (MALAJOVICH, 2016)

Com o advento da Segunda Guerra Mundial houve a necessidade da evolução da medicina, com o desenvolvimento de antibióticos como a penicilina, produzida através de processos biotecnológicos propulsionados por Alexander Fleming, para tratar os feridos e combater as infecções causadas pela guerra. (CARRER et al., 2010; VARGAS et al., 2018)

O primeiro conceito de biotecnologia foi criado pelo engenheiro Húngaro Karl Ereky em 1919, e com a constante evolução e inovação da mesma vários conceitos forem destinados para sua definição, com a utilização de diferentes métodos que muito contribuíram para a qualidade de vida englobando os mais diversificados segmentos como a biologia molecular, genética, bioquímica, processos imunológicos, robótica, alimentação dentre outros. A bióloga Maria Antonieta Malajovich conceitua biotecnologia como:

Consideraremos a biotecnologia de uma maneira ampla, definida como uma atividade baseada em conhecimentos multidisciplinares, que utiliza agentes biológicos para fazer produtos úteis ou resolver problemas. Esta definição é suficientemente abrangente para englobar atividades tão variadas como as de engenheiros, químicos, agrônomos, veterinários, microbiologistas, biólogos, médicos, advogados, empresários, economistas etc. (MALAJOVICH, 2016, p. 2).

A biotecnologia ao longo do tempo se ramificou em 2 vertentes: Biotecnologia clássica e biotecnologia moderna, em decorrência de pesquisas e avanços do homem no que tange usar a natureza em seu benefício, obtendo melhores resultados e aperfeiçoamento de espécies com técnicas modernas em prol dos seres humanos,

Considera-se biotecnologia clássica as técnicas de fermentação utilizadas na antiguidade, com a utilização de organismos encontrados na natureza e biotecnologia moderna onde se utiliza conceitos engenharia genética, a criação de novos produtos como: farmácia, agricultura, medicina, indústria, meio ambiente. (MALAJOVICH, 2016)

\subsubsection{Biotecnologia moderna e organismos geneticamente modificados (OGMs)}

A bifurcação entre a antiga e nova biotecnologia, conceito este que está em constante evolução, se deve a uma gama de pesquisas realizadas por H. Boyer e S. Cohen em Stanford e na University of Califórnia em 1973, que durante seus experimentos introduziram um gene de rã em uma bactéria. Através deste experimento foi possível mudar o programa genético de um organismo transferindo-lhe genes de outras espécies. A biotecnologia moderna também 
chamada de engenharia genética ou tecnologia do DNA recombinante, com o manuseio do material genético favorecendo o cultivo de plantações, biofármacos, fertilizantes, aumento de alimentos em quantidade e qualidade entre outros. (MALUF, 2015).

Transgênico é de acordo com Borém e Santos (2003), “um organismo cujo genoma foi alterado pela introdução de DNA exógeno, que pode ser derivado de outros indivíduos da mesma espécie, de uma espécie completamente diferente ou até mesmo de uma construção gênica sintética” (p. 297-298).

Os organismos modificados foram criados pelo homem, com o intuito de favorecer atributos pertinentes a objetivos específicos tais como: melhoria de espécies, industrialização, produção de fármacos, alimentação, vacinas entre outros ocasionados pela manipulação e introdução de genes que podem ser de um ou mais, através de métodos da biologia molecular.

O primeiro OGMs que teve sua estrutura original alterada foi a bactéria Escherichia coli, com a inserção de material genético humano para a elaboração da insulina (VARGAS et.al., 2018). Apesar de ser usados como sinônimo nem todos os OGMs são transgênicos, pois esse recebe parte de material genético de uma espécie diferente com tecnologia recombinante, enquanto um OGMs recebe material de outro organismo, mas de mesma espécie. (VARGAS et al., 2018).

\section{BRASIL: IMPACTOS DOS OGMS NO AGRONEGÓCIO}

As bases da economia brasileira estão enraizadas na agricultura, que com o passar do tempo evoluiu de um sistema agrícola autônomo, produtor de insumos, equipamentos e implementos agrícolas, para um mantenedor de matérias primas destinada ao consumo limitado ao país ou para a exportação.

Toda está evolução e expansão da urbanização, das indústrias, comércio fez com que o setor agrícola evoluísse e acompanhasse tais mudanças especializando-se em técnicas para melhorar a produtividade, distribuição de insumos e implementos, fazendo a ponte entre produtores rurais, indústrias e comércio.

O encadeamento de setores econômicos que vem desde da produção, indústria, comércio, mercado e consumidor tendo como elo a agricultura fez com que surgisse um novo termo, o agronegócio. Conceito este que representou 24,31\% do PIB brasileiro em 2020, e 
segundo os dados do Centro de Estudos Avançados em Economia Aplicada, da Esalq/USP e Confederação da Agricultura e Pecuária do Brasil (CNA) cresceu entre janeiro e junho cerca de 5,26\%, de acordo com CNA e Esalq alavancando o setor econômico do país, demonstrando o quanto é importante seu crescimento garantindo desta forma uma posição favorável frente a produtores mundiais. (CEPEA, 2020)

Nas últimas décadas a produção de OGMs atingiu vertiginosamente vários pontos do mundo. A competividade e a busca por mercados fizeram com que muitos países adotassem a produção de organismos modificados, através da biotecnologia com técnicas de engenharia genética possibilitou a geração de espécies modificadas mais resistentes a herbicidas e plagas, maior produtividade, qualidade das plantações, características selecionadas de acordo com interesse e mercado do produtor, extensão em hectares produtivos e a redução de gastos.

O EUA foi o precursor na utilização da biotecnologia, incialmente na medicina, produção animal e vegetal na década de 70, e em 1980 a soja, o milho e o tomate sendo que os organismos geneticamente modificados só puderam ser comercializados no final de 1990. Os estadunidenses deram o passo inicial para comercialização de transgênicos em 1996, adotando a soja como produto geneticamente modificado.

A utilização de OGMS no Brasil teve início em 1996, quando produtores brasileiros estavam tendo sérios problemas com plantas daninhas que prejudicavam o cultivo de soja e propiciando danos econômicos, em contrapartida as plantações dos argentinos cresciam saudáveis. Este foi o início do uso de OGMs e os benéficos que o mesmo poderia trazer ao agronegócio.

Contudo apenas em 1998 que foi aprovado o plantio de soja transgênica pela Comissão Técnica Nacional de Biossegurança (CTNBio), instituição criada para averiguar a segurança dos organismos geneticamente modificados, sendo criada a lei $n^{\circ} 11.105 / 2005$ que estabelece as normas de segurança e físcalização no que concerne aos OGMs.

De acordo com Bórem e Santos (2008) a biotecnologia moderna aplicada aos organismos modificados permite um aumento da produtividade, espécies adaptadas a solos improdutivos, controle e combate a pragas, redução de custos e maior rentabilidade. Desta forma a Brasil consegue manter e alavancar suas exportações no setor agrícola e consequentemente o agronegócio cresce, aumentando o PIB. 
Até meados de 2017 cerca de 70 OGMS foram aprovados no Brasil, e tal crescimento deve se aos benefícios que tais organismos acarretam ao agronegócio, sendo que os principais produtos comercializados pelo Brasil são soja, milho (verão e inverno) e algodão. A área de transgênico cultivadas no país correspondia em 2017 a 50,2 milhões de hectares de extensão só ficando atrás dos EUA que possuía em média 75 milhões de hectares. É indiscutível a rentabilidade proporcionada pelos OGMS. (CIB E AGROCONSULT, 2018)

De acordo com dados da Agroconsult e CIB (2018) a produção de variantes de transgênico de soja supera em $26 \%$ a semente convencional, no caso do milho inverno é ainda maior com um percentual de 152\%. Com estes índices comprova-se os ganhos em área produtiva, por serem mais resistentes a invasores sejam eles: insetos, lagartas e plantas daninhas aumentando desta forma o volume em toneladas para as exportações.

Dados obtidos através de estudos elaborados pela Céleres (2012) por intermédio da Associação Brasileira de sementes e mudas (Abrasem) exibe que na agricultura devido as novas tecnologias obtiveram um montante de US\$ 18,8 bilhões em 16 anos sendo que deste valor a maior parte corresponde aos produtores rurais é cerca de $81 \%$ e 19\% para a indústria.(GOMES E BORÉM, 2015)

Os ganhos na rentabilidade fazem referência ao uso de OGMs, com custos menores para produtores rurais refletindo em um lucro de 35,8 bilhões, rendimento este proveniente da utilização da biotecnologia e suas implicações, gerando divisas para todo país. O PIB devido a adoção de transgênicos representou em 2018, 2,8 bilhões de renda. (CIB. Agroconsult, 2018)

A agricultura impulsiona o setor econômico no país, pois está entrelaçada à uma cadeia de negócios que engloba fornecedores, setor civil, comércio entre outros. Desta forma os OGMs trouxeram vários benefícios ao agronegócio, tanto na produtividade, geração de lucros e empregabilidade ocasionando um montante considerável de divisas ao país.

\section{ORGANISMOS GENETICAMENTE MODIFICADOS PONTOS E CONTRAPONTOS}

\subsection{OGMs e alimentação mundial}

Segundo dados da Food and Agriculture Organization (FAO, 2014), uma em cada 10 pessoas no mundo, não possuem alimentação adequada e suficiente para sobreviver de forma 
saudável e digna. De acordo com as estimativas da ONU em 2024, a população mundial será de 8 bilhões de seres humanos e em 2050 acima de 9,5 bilhões. A demanda por alimentos em virtude do crescimento do número de pessoas e poder de compra ocasiona preocupação em relação a quantidade de alimentos produzidos no mundo será suficiente para contingente populacional que cresce em ritmo acelerado.

Cerca de 90\% de áreas produtivas para agricultura estão na América Latina e na África Subsaariana em países como: Brasil, Congo entre outros (FAO, 2014). A problemática é a extensão em hectares produtivos em alimentos como soja, milho e algodão poderá não ser o bastante para alimentar o mundo.

Com o advento de novas tecnologias e a utilização de variantes de OGMs será possível ampliar em larga escala a áreas cultivadas e úteis para diminuir a fome mundial (SAATH e FACHINELLO, 2018). Tal perspectiva se deve ao aumento em hectares cultivados, maiores colheitas, organismos mais resistentes a pragas, paletas invasoras, insetos, crescimento muito mais rápido do que variantes convencionais entre outros.

Os organismos geneticamente modificados são um forte aliado para o aumento de alimentos no mundo, pois supera em produtividade, tempo menor de maturação para a colheita, resistência aos organismos invasores e posterior mercado consumidor, desta forma é viável suplantar a carência de alimento no mundo.

\subsection{Senso Comum e OGMS}

A utilização de transgênicos desde o surgimento das primeiras culturas até os dias atuais ainda é objeto de várias discussões, polêmicas, com opiniões favoráveis ou contrárias, produtores e pesquisadores de um lado e órgãos não governamentais ou uma ramificação do governo no que concerne à mesa do consumidor.

Um dos pontos em debate é o aparecimento de problemas de saúde a longo prazo, como caso de câncer ou desenvolvimento de alguma patologia, porém não há nenhum indicio de podem ocorrer. As preocupações em relação ao uso de alimentos geneticamente modificados é o receio da ocorrência de efeitos inesperados produzidos pela transferência de material genético, da produção de novas proteínas alergênicas, da produção de compostos tóxicos, e da redução da qualidade nutricional dos alimentos ( PAIVA e DAMASCENO, 2020). Mas segundo dados da (FAO, 2014), as culturas modificadas geneticamente são iguais, 
não existindo diferença no quesito nutricional em relação às sementes naturais, a não ser que haja interesse em aumentar algum nutriente ao longo do processo.

No Brasil e no mundo existem vários protocolos de segurança, para garantir o uso dos transgênicos de maneira que não cause danos população, como protocolo de Cartagena, a obrigação do uso de rotulagem de produtos transgênicos, a Comissão técnica Nacional de Biossegurança (CTNBio). (PAIVA e DAMASCENO, 2020)

A Codex Alimentarius Commision, da FAO adotou em 2013 uma lista com princípios para análise de risco para os transgênicos. Segundo Camara et al. (2009) são analisados os efeitos para a saúde, a tendencia de ocasionar reações alérgicas, componentes com propriedades tóxicas ou nutricionais, efeitos associados com a modificação genética, estabilidade de gene. Sendo assim é realizado um processo longo de pesquisas e avaliações para que a liberação seja segura e sem causar qualquer dano durante a sua utilização.

\section{PROCEDIMENTOS METODOLÓGICOS}

O presente artigo foi desenvolvido por meio de pesquisa em artigos, revistas e informações disponibilizadas pela Organização das Nações Unidas (ONU) e autores especializados no assunto, sendo uma revisão bibliográfica qualitativa e quantitativa sobre os organismos geneticamente modificados.

As bases de dados utilizadas para a pesquisa foram a Scielo, google acadêmico, Portal Capes e livros da autora Malajovich, fontes confiáveis e especializadas nos assuntos há anos, os critérios de inclusão e exclusão são artigos a partir do ano de 2000 em diante e revistas consagradas no assunto, em formato digital e na íntegra.

\section{RESULTADOS E DISCUSSÃO}

Com toda a expansão da agrobiotecnologia pelo mundo e os benefícios que proporciona aos diversos setores, principalmente a agricultura, o Brasil não poderia ficar de fora desta evolução. Com a adesão de transgênicos, o país alcançou patamares altíssimos de rentabilidade e produtividade, sendo que em 2017 (quadro 1), ocupava um ranking de segundo lugar na 
produção de transgênicos no mundo, ficando apenas atrás do EUA de acordo com a dados do Serviço Internacional para Aquisição de Aplicações em Agrobiotecnologia. (ISAAA, 2017).

Quadro1: Os 5 países com maior área de cultivo de transgênicos em 2017.

\begin{tabular}{|l|l|l|l|}
\hline Ranking & País & Extensão em hectare & Tipos de Cultivo \\
\hline 1 & EUA & 75,0 & $\begin{array}{l}\text { Milho, soja, algodão, canola } \\
\text { entre outros }\end{array}$ \\
\hline 2 & Brasil & 50,2 & Soja, milho, algodão \\
\hline 3 & Argentina & 23,6 & Soja, milho, algodão \\
\hline 4 & Canadá & 13,1 & Canola, milho, soja \\
\hline 5 & Índia & 11,4 & Algodão \\
\hline
\end{tabular}

Fonte: ISAAA (2017).

Toda a dinâmica na utilização de transgênicos no Brasil justificam a sua escolha, pois ampliou consideravelmente os lucros em relação as sementes convencionais. Segundo uma pesquisa da CIB e Agroconsult (2018), o milho foi a maior responsável pelo aumento da receita com cerca de $\mathrm{R} \$ 20,1$ bilhões, seguido da soja com uma rentabilidade de $\mathrm{R} \$ 4,8$ bilhões e por último o algodão com R $\$ 0,3$ bilhões.

Um aspecto importante dos OGMs condiz com alimentação mundial, no que concerne à insuficiência de plantio de alimentos para todos os países que enfrentam problemas com clima e solo para produzirem, uma vez que os OGMS são mãos resistentes, com maiores índices em produtividade em um curto período em relação as plantas convencionais, além da conservação da biodiversidade (ISAAA, 2017)

Os OGMS contribuem muito para o país que o adota, seja para o agronegócio, alimentação mundial, rentabilidade fatos estes comprovados pelo Agroconsult e ISAAA. Quanto a segurança na utilização dos mesmos, através da Academia Nacional de Ciências, Engenharia e Medicina dos Estados Unidos composta por 50 países pelo relatório, respaldaram a segurança no uso de culturas geneticamente modificadas. 
A adoção da biotecnologia e consequentemente o uso de sementes modificadas alterou consideravelmente as produções rurais, na maioria dos países. No Brasil a produção de soja, milho e algodão alavancou lucros e produtividade repercutindo em todo país e contribuindo para o PIB e agronegócio. É inegável os benéficos das plantas modificadas no que concerne resistência a pragas, invasores e produção de alimentos em decorrência da demanda e do crescimento populacional.

Em mais de 20 anos de utilização de OGMs, segundo relatórios oficiais, não foi registrada nenhum malefício a saúde. A falta de informação ou distorção favorecem a repulsa na utilização dos mesmos por muitas pessoas, causando polêmica e discussões sem fundamento.

Desta forma a biotecnologia está cada vez mais presente no mundo, pela necessidade de inovar e evoluir, é imprescindível que pesquisas continuem sendo feitas na utilização de OGMs, para desmistificar mitos e comprovar fatos de cunho científico em prol da saúde da população.

\section{REFERÊNCIAS}

BORÉM, A.; SANTOS, F. R. Biotecnologia simplificada. 2. ed. Viçosa: Editora UFV. Viçosa, 2003.

BORÉM, A.; SANTOS, F. R. Entendendo a biotecnologia. Editora UFV. Viçosa, 2008.

CAMARA, M. C. et al. Transgênicos: avaliação da possível (in)segurança alimentar através da produção científica. Hist. cienc. saúde-Manguinhos, Rio de Janeiro, v. 16, n. 3, p. 669681, Set 2009. Disponível em: $<$ https://www.scielo.br/pdf/hcsm/v16n3/06.pdf $>$. Acesso em 7 mar. 2021.

CARRER, H.; BARBOSA, A.L.; RAMIRO, D.A. Biotecnologia na agricultura. Dossiê Biotecnologia Estudos Avançados 24 (70), 2010. Disponível em:< https://www.scielo.br/j/ea/a/rckkXMJ7cc6hxPhbNFhVWGm/?lang=pt\&format=pdf $>$. Acesso em 7 mar. 2021.

CÉLERES. Relatório Biotecnologia. Relatório Técnico. Disponível em: http://celeres.com.br/wordpress/wp-content/uploads/2012/12/RelBiotecBrasil_1201_vf.pdf.> Acesso em: 15 mar. 2021. 
CEPEA. PIB do agronegócio brasileiro Disponível em:

$:<$ https://www.cepea.esalq.usp.br/upload/kceditor/files/Cepea_PIB_1semestre_2020(1).pdf. Acesso em: 10 mar. 2021.

CIB; AGROCONSULT. 20 anos de transgênicos: benefícios ambientais, econômicos e sociais no Brasil. 2018. Disponível em: <

https://croplife.storage.googleapis.com/1/2019/10/Vinte-anos-transgenicos.pdf $>$. Acesso em : 20 mar. 2021.

CODEX ALIMENTARIUS. International Food Standards. Disponível em:

$<$ http://codexalimentarius.net/standards/stand.htm>. Acesso em: 5 mar. 2021.

FAO. The state of food insecurity in the world 2014. Food and Agriculture Organization of the United Nations. Home. Disponível em: <http://www.fao.org/publications/sofi/en/>.

Acesso em: 6 mar. 2021.

GOMES, W. S.; BORÉN, A. Biotecnologia: Novo paradigma do Agronegócio Brasileiro. Revista de Economia e Agronegócio, vol.11, $\mathrm{n}^{0}$ 1, 2015. Disponível em:< https://periodicos.ufv.br/rea/article/view/7539> Acesso em: 12 mar. 2021.

ISAAA. Situação Global dos Cultivos de Transgênicos em 2018. Disponível em < https://d335luupugsy2.cloudfront.net/cms/files/50569/15306214042018-07-03-ISAAAResumo-Executivo.pdf > Acesso em: 15 mar. 2021.

MALAJOVICH, M. A. Biotecnologia. Rio de Janeiro: BTeduc, 2016. Disponível em: < https://www.academia.edu/download/60857043/livro_de_biotecnologia_20162019101013504-1hrhnzv.pdf $>$. Acesso em: 11 mar. 2021.

MALUF, A. C. R. F. D. Curso de Bioética e Biodireito. 3ª ed. São Paulo: Atlas, 2015.

National Academies of Sciences, Engineering, and Medicine. Genetically Engineered Crops: Experiences and Prospects. The National Academies Press, Washington, DC, 2016. Disponível em: $<$ https://www.nap.edu/catalog/23395/genetically-engineered-cropsexperiences-and-prospects>. Acesso em: 1 mar. 2021.

ONU. Cartagena Protocol on Biosafety to the Convention on Biological Diversity: text and annexes. Montreal: United Nations, 2000.

ONU. Declaração do Direito ao Desenvolvimento. Disponível em:<

http://www.dhnet.org.br/direitos/sip/onu/spovos/lex170a.htm>. Acesso em: 25 fev. 2021.

ORGANIZAÇÃO MUNDIAL DA SAÚDE (OMS). Convenção sobre Diversidade Biológica, 2008.

PAIVA, M. J. M.; DAMASCENO, I. A. M. O uso de dos alimentos geneticamente modificados: Principais desafios. Revista Multidebates, v. 4, n. 3, Palmas-TO, 2020. 
SAATH, K.C.O.; FACHINELLO,A.L. Crescimento da demanda mundial de alimentos e restrições do fator terra no Brasil. Ver. Econ. Rural 56 (2), 2018.

VARGAS, B. D. et al. Biotecnologia e Alimentos Geneticamente Modificados: Uma Revisão. Revista Contexto \& Saúde, v. 18, n. 35, p. 19-26, jul./dez. 2018. Disponível em:< https://www.revistas.unijui.edu.br/index.php/contextoesaude/article/view/5591>. Acesso em: 5 mar. 2021. 